\title{
Patient Perception and Choice Factors Related to International Hospitals: A Study in Ho Chi Minh City, Vietnam
}

Lena Bucatariu ${ }^{1}$ and Babu P George ${ }^{2 *}$

${ }^{1}$ Department of Management, SMC University, Switzerland

${ }^{2}$ Department of Management, Fort Hays State University, USA

\begin{abstract}
In the background of stagnant home markets, health care firms from mature economies are looking for opportunities in developing markets such as Vietnam. Various studies on marketing of health care from developed economies show convenience, specialties, reputation, and word of mouth as major choice factors for hospitals. The limited number of consumer behaviour articles from developing economies has contradictory findings for private and public hospitals with no mention of international hospitals. In this paper, the authors investigate the choice criteria and consumer perceptions of international hospitals in Ho Chi Minh City. Findings imply that younger consumers prefer private care as they suffer from minor illnesses and prioritize convenience, customer service and comfortable facilities. Some older patients are more conservative, seeking government sites due to trust, familiarity and insurance coverage. Irrespective of age and income, all those who experienced international hospitals where left with a lasting positive impression of the caring consultation and staff, modern equipment, and 'VIP feel' of facilities, with price quoted as the main barrier.
\end{abstract}

Keywords: Health care; Vietnam; Private hospitals; International hospitals; Choice factors; Customer behaviour

\section{Introduction}

With the increase in globalization, developing markets are the target of a growing number of health care providers from mature economies such as International SOS (London), CMI (France), and Fortis Group (from Singapore). Current world health care spending has been estimated at around $\$ 7.2$ trillion or $10 \%$ of world GDP [1] and projected to reach $\$ 18$ billion by 2020 [2]. Within Asia, Vietnam has an average spend of $6.4 \%$ of GDP on health care, which places it higher than Myanmar (2\%) and Laos (4.5\%), but lower than more developed economies, e.g. Japan at $10 \%$ of GDP [3].

Despite high spending, the public sector in Vietnam suffers from congestion, is only partially insured, and plagued by corruption [4]. With a growing middle class and increase in lifestyle diseases, the market offers great opportunities for international firms, as imports account for $80 \%$ of pharmaceuticals and over $90 \%$ of medical devices [5]. Facilitated by WHO initiatives and the recently signed TPP, private health spending is captured by a few foreign and joint-venture hospitals which cater to the affluent segments in Hanoi and Ho Chi Minh City [6].

According to the literature reviewed, customer perceptions and choice factors are an important part of the Information search and Evaluation of alternatives stages in the decision-making process [7]. In mature economies, hospital choice tends to be governed by convenience, customer care, reputation, and specialties available, among others. In developing economies, more basic factors such as price and facilities play a major role, along with hospital reputation, and estimated value of bribe needed. The literature on the superiority of private v. public health care has been so far inconclusive, as in some developing economies government hospitals appear to fare better on doctor expertise and efficacy of treatment, but lag behind in resourceintensive dimensions such as staff training and operational efficiency. For Vietnam, studies mostly focus on social insurance coverage and affordability of government hospitals, with few investigations into private care and none dedicated to international providers.

The current study aims to investigate the perceptions of local patients towards international health care in HCM City, drivers and barriers towards local v. foreign hospitals, and the main criteria influencing the decision-making process. The report starts with an overview of literature relevant to evaluation of alternatives in the decision-making stage, in particular perceptions and choice factors of hospitals, followed by methodology and data collection of 11 qualitative interviews, analysis of findings using coding and verbatim, discussion of results, implications and conclusion.

\section{Literature Review}

This section reviews the steps in the consumer-decision process, with an emphasis on evaluation of alternatives and country of origin effects for international service providers. Next, choice factors are analysed for hospitals in mature and developing economies, followed by an overview of the health care system in Vietnam.

\section{The consumer decision-making process}

Defined as 'the process of making purchase decisions based on cognitive and emotional influences such as impulse, family, friends, advertisers, role models, moods, and situation that influences a purchase' [7], the consumer decision-making process explains how and why consumers make purchases. Need recognition or Problem recognition [5] refer to the stimuli that trigger the consumer's awareness of the gap between reality and the desired state? During Information Search, the consumer uses commercial sources (company website, brochures) and informal input (family recommendations, e-word-of-mouth) to find 'solutions' for the identified need. Evaluation of alternatives happens somewhat simultaneously as it involves critically appraising competing offerings and judging the benefits and risks of various options. With

*Corresponding author: Babu P George, Department of Management, Fort Hays State University, USA, Tel: (785) 628-4778; E-mail: bpgeorge@fhsu.edu

Received July 07, 2017; Accepted July 17, 2017; Published July 21, 2017

Citation: Bucatariu L, George BP (2017) Patient Perception and Choice Factors Related to International Hospitals: A Study in Ho Chi Minh City, Vietnam. J Health Med Informat 8: 277. doi: 10.4172/2157-7420.1000277

Copyright: @ 2017 Bucatariu L, et al. This is an open-access article distributed under the terms of the Creative Commons Attribution License, which permits unrestricted use, distribution, and reproduction in any medium, provided the original author and source are credited. 
a set of expected benefits in mind, the prospect may proceed with the Purchase decision, choose a substitute or even abandon the process [8]. Finally, at the Post-purchase evaluation stage the buyer would experience satisfaction if the need was fulfilled or dissonance, if the result falls short of expectations [9]. Along similar lines, Kotler proposes the Black Box model to explain internal influences on the buyer's mind [10], including personal factors such as perception, motives, values, and lifestyle.

\section{Evaluation of alternatives}

For the purpose of this report, the analysis will focus on the PrePurchase Search and Evaluation of alternatives stages [7] as they are most relevant to consumer perception and choice criteria. Defined as 'the process by which an individual receives, selects, organizes, and interprets information' [9], perception depends on internal consumer factors such as beliefs, past experience and mood, and is influenced by the intensity of the stimulus received (e.g. olfactory cues in a hospital) and the context. During the comparison stage, consumers will shortlist several competing offers and try to predict functional outcomes (treatment efficacy) and their psychosocial consequences (relief of care givers). By summing up objective evaluative criteria such as price or warranty and subjective factors including image and design, expectations combine in the consumer's mind to form attitudes, i.e. learned predispositions to respond to an object [9].

\section{Country of origin effects on international service providers}

The complexity of product evaluation escalates with the inclusion of non-domestic brands, especially in the case of services where quality cues and outcomes are mostly intangible. Although studies abound on country of origin effects for FMCG and luxury goods, little research is available regarding international services. A recent study on performing arts [11] found that Indian youth overwhelmingly prefer entertainment content from the US across all categories, have a positive attitude towards UK movies, and high consumption intention for Russian circus. A German study [12] found that buyers of foreign services are likely to form purchase intentions based on alternative quality indicators such as country of origin, brand name, and warranty for safety of banks and budget airlines.

\section{Choice criteria for health care}

Another high-involvement sector relevant to safety needs is health care, where high anxiety over physical and psychosocial risks influences the patient's ability to assess service outcomes [13]. A summary of literature (Table 1) revealed quality of care, cleanliness, specialized services, price, and reputation among the main hospital evaluation criteria [14]. An older US study among the urban poor [15] found that most patients were willing to switch hospitals for convenience, but would stay for quality of care and familiarity with the site. When the comparison was drawn between public and private care, a Turkish study highlighted accessibility, image, and physical appearance as major attributes [16] favouring private hospitals (Table 1).

A paper on quality dimensions [17], investigated the impact of patient perceptions of unobserved attributes such as reputation on hospital choice. It was found that perceptions of reputation and medical services, including high clinical scores, had a strong impact on the final decision. In Turkey, customers relied on the behaviour and attitude of PR personnel to derive quality cues [18]. An Italian survey [19] went one step further to gauge not only the level of influence but also the consequences of social interaction on patients' choice of hospital. The authors uncovered word of mouth, past experience, convenient access, and a low doctor-to-patient ratio as key variables in hospital decision. When analysing the viability of the decision made based on word-ofmouth, it was found that following informal sources may result in low quality treatment.

\section{Hospital choice factors in developing economies}

On the background of public hospital congestion, inadequate infrastructure, and insufficient insurance coverage, patients in emerging markets are more likely to set their purchase on basic factors such as price and infrastructure. In the case of tertiary hospitals (e.g. oncology, organ transplant, neurosurgery, etc.) in India, the referral decision is often made by the family in collaboration with the specialist doctor and takes into account basic amenities, hospital reputation, and budget $[20,21]$. When the doctor is not involved, Indian patients will favor multi-specialties and follow word of mouth [22] while Bangladeshi will evaluate the amount of kickback (baksheesh) required in addition to the published fees [23].

In terms of actual service delivery, findings are somewhat contradictory. Although higher financial backing and international know-how should translate into better quality of private and foreign hospitals, Rannan-Eliya et al. [24] found that Sri Lankan public hospitals performed better in overall medical effectiveness, but worse for resource-intensive dimensions such as interpersonal skills and turnaround time. In contrast, Indian patients felt more assured with the reliable personnel and modern equipment in private hospitals. In Nigeria, overall perception was positive for both, although scores for private providers increased when high-level government hospitals were excluded from the comparison [25].

\section{Vietnam hospitals overview}

As a result of deregulation, Vietnam's health care system has become more competitive with private and foreign options, but significant increases in out-of-pocket expenses have led to criticism of over-treating patients to grow revenue [26]. Following recent health care reforms, about $71 \%$ of Vietnam's citizens are a registered social health insurance user, which covers $100 \%$ of costs for ethnic minorities and up to $80 \%$ for the poor and semi-poor (Vietnam accelerates universal health insurance, 2015). Still, affordability remains a key issue for the lower income bracket, with estimates placing an additional $14 \%$ of the population below the poverty line if health user charges were included [27].

Private care options include non-government local, joint-venture, and foreign hospitals and clinics, as well as evening clinics where doctors practice privately. Despite higher charges, private clinics were the first stop in about $60 \%$ of all illness episodes, followed by self-treatment in $23 \%$ of episodes or no treatment for the cash-strapped urban [28]. Gender wise, women were more likely to see a doctor while men tended to forego treatment or rely on the pharmacist's advice [28]. In rural areas, treatment was often financed through borrowing or wiped out the household savings [29] leading to a 'medical poverty trap'. With insurance, health expenses were reduced by as much as two thirds [30], hospital stays prolonged [31] and fewer days were missed from work or school [32].

Although top tuberculosis hospitals have excellent track records and are affordable, evidence showed strong preference for private care in the treatment of this disease. Lonnrith et al. [33] found that TB patients were drawn to the private sector's flexibility of diagnostic procedures, and its hassle-free, anonymous treatment. Moreover, the authors could not trace a significant relationship between the patient's socioeconomic class and the use of private providers, also confirmed by Nguyen et al. 


\begin{tabular}{|c|c|}
\hline Authors and year & Findings-choice factors and perceptions public v. private \\
\hline Taylor and Cosenza, 1999 & Quality of care, cleanliness, specialized services, price, reputation \\
\hline Skinner and Price, 1977 & US: Switch for convenience, stay for quality of care, familiar site \\
\hline Akinci and Esatoglu, 2004 & Turkey: Prefer private hospitals for accessibility, image, appearance \\
\hline Jung et al., 2011 & Patients favor hospitals with high clinical scores, reputation \\
\hline Taylor and Cosenza, 1999 & Turkey: Derive quality cues from behavior of PR personnel \\
\hline Moscone et al., 2012 & $\begin{array}{l}\text { Italy: Word of mouth, past experience, convenient access, and a low doctor-to-patient ratio; following WOM sometimes } \\
\text { results in poor quality of treatment }\end{array}$ \\
\hline Kamra et al., 2016 & India, with doctor referral: Family helps decide based on amenities, reputation of hospital, budget \\
\hline Bhangale, 2011 & India, no doctor referral: Multi-specialties, word of mouth \\
\hline Andaleeb, 2001 & Bangladesh: Added criterion of how much kickback must be paid \\
\hline Rannan-Eliya et al., 2015 & Sri Lanka: Public hospitals-better doctors and treatment, private: better customer care and turnaround time \\
\hline Singh, 2013 & India: prefer private hospitals as feel more reassured in the quality of treatment, impressed by responsive personnel \\
\hline Polsa et al., 2011 & $\begin{array}{l}\text { Nigeria: Positive overall perception for both sectors, higher for private after excluding high-level government hospitals } \\
\text { from the comparison }\end{array}$ \\
\hline Huong et al., 2007 & Vietnam, public: Too many out of pocket expenses \\
\hline Nguyen and Lofgren, 2008 & Vietnam: Private care preferred as first contact (faster turnaround, convenient access) \\
\hline Jowetta and Contoyannis, 2002 & Vietnam: Both sectors benefit as long as they accept social health insurance \\
\hline Lonnrith et al.,2001 & Vietnam, private: patients with tuberculosis vastly prefer private care for anonymous treatment, flexible diagnosis \\
\hline Nguyen et al., 2002 & $\begin{array}{l}\text { Vietnam, private: Preferred for minor illnesses across all income groups, especially families with children. Public hospital } \\
\text { chosen when hospitalization needed (higher \% covered by insurance) }\end{array}$ \\
\hline
\end{tabular}

Table 1: Authors and year (Findings-choice factors and perceptions public v. private).

[34]. Finally, private care was most common for young children and in households with several sick members, while public hospitals were chosen for in-patient treatment of major illnesses.

\section{The Research Gap}

From an academic perspective, the health care industry is relatively well-researched, although in areas not related to consumer behaviour of patients in developing economies. For instance, various studies have been conducted at government-funded hospitals on social health insurance [35], health care benefits [36] or health care management education [37]. Even studies relevant to consumer buying behaviour tend to be carried out at local public hospitals rather than foreign providers and in mature economies such as US [38], UK [39] or Australia [40] or in neighbouring countries such as India and Sri Lanka. As seen above, Vietnamese research focuses mostly on the economics of social health insurance and affordability, with few considerations for non-financial factors. Additionally, although several studies have investigated perceptions of private hospitals, none dealt with users of international and foreign joint-venture health care providers.

\section{Propositions}

To fill the gaps above, the current study aims to research international health care choices from the point of view of local patients in a developing economy, Vietnam, with a focus on consumer buying behaviour. Thus, the proposed main question and sub-questions are:

What are the choice criteria and consumer perceptions of international and foreign-joint venture hospitals in Ho Chi Minh City?

- What are key choice criteria for local patients at international hospitals in HCMC?

- How do HCMC patients perceive international hospitals v. local public and private hospitals?

- What are key drivers and barriers when choosing international hospitals?
Considering other research in developing economies within the region, the current study proposes the following propositions specific to Vietnam

P1: Price is not the main factor in the decision-making process for international hospitals.

Despite numerous studies placing affordability as a key criterion, preference for private care did not appear to be specifically tied to socioeconomic class of Vietnamese patients (Nguyen, Berman, \& Larsen, 2002). This hypothesis will test whether the apparently independence between income and choice of private care can be extrapolated to the usage of international hospitals, where costs are up to four times higher than for private local hospitals.

P2: Vietnamese patients have a positive attitude towards international hospitals compared with local public or private hospitals.

According to cultural research, Asian consumers are more likely to derive quality from 'borrowed' cues such as endorsement by opinion leaders, international affiliation, awards and certificates $[9,41,42]$. As the literature showed wide differences of opinion on the effectiveness of public and private care in various developing economies, but did not directly measure perceptions of international hospitals, this hypothesis aims to test to what extent Vietnamese patients are influenced by foreign affiliation of hospitals.

P3: The patient's age influences their perception of international hospitals compared with local public or private hospitals.

Studies from various industries have demonstrated that younger customers tend to be more open to new ideas and likely to try and adopt innovative products, while older consumers are loyal to familiar brands in order to minimize risks [7]. On the other hand, Vietnam scores highly on the cultural dimensions of uncertainty avoidance and risk-avoidance, which are associated with low innovation. Therefore, it would be interesting to gauge the extent to which the patient's age may override cultural tendencies to impact on international hospital perceptions. 


\section{Research Methodology}

\section{Research design}

The study employed the inductive method [43-45] in an exploratory investigation of patient perceptions and choice criteria for international hospitals. Face-to-face qualitative interviews were deemed a suitable method for collecting richer insight into each patient's personal experience, attitude, and perceptions [45]. In addition, health care can be a delicate topic; therefore personal interviews offered the adequate level of privacy for the researcher to probe into the hospital decisionmaking process.

\section{Data collection}

Interviews of about 20-35 min were conducted face-to-face with 11 patients, of which 6 patients under 40 and 5 patients aged 40 and above. The sample size was determined based on the principle of saturation [45] in order to increase credibility. To be included, respondents had to be over 18, Vietnamese, living in HCM City, who had received treatment at an international hospital at least once within the previous 6 months. To vary the depth of experience, a quota of three respondents had to have undergone some serious intervention that required hospitalization, surgery, or repeated follow-up visits. Respondents were intercepted around District 10 of HCM City, as this area is considered a medical hub with over 30 local and international hospitals (Hospitals in HCM City and Southern Provinces, 2016).

The authors drafted a topic outline with main and probing questions, which were reviewed with a local research director then translated into Vietnamese. Two pilot interviews were conducted to test reactions, brainstorm more probing directions, and estimate duration. The actual interviews were conducted by an experienced local interviewer (as the author does not speak Vietnamese) who introduced herself, explained the purpose of the research, and clarified ethical and privacy concerns. The interviewer got permission to use an audio recorder and took notes on body language for later review. Transcripts were translated into English and then coded [45] based on recurrent issues. Later, the author prioritized major themes by relevance and highlighted useful quotes for reproduction in the actual paper.

\section{Limitations}

Although care was taken to ensure high utility and credibility of data collection, the paper does have some limitations, namely: The sample size is small and non-random (to maximize relevancy of respondents); the study area is limited to a relatively wealthy district of HCM City, which means the insight collected may not be extrapolated to patients in North and Central Vietnam or in smaller towns; additionally, the investigation is a snapshot of the current situation and lacks the longterm orientation perspective that a longitudinal study would have provided.

This paper stemmed from the graduate research project of the first author: due to time and resource limitations, data could not have been collected from regions outside of the Ho Chi Minh City. The findings should be interpreted cautiously and broader generalizations may not be made. That said, regional factors and diversity across patient samples aside, the findings should be able valid to other population groups [13,46-49].

\section{Data Analysis}

Based on the data collected, there are some differences in the attitude and choice criteria of local v. international hospitals among younger patients compared to the older group. This section will start with patient profiles, then analyse their perceptions of foreign versus local hospitals and finally summarize the key criteria for international care.

\section{Patient profile}

All of the younger patients (late 20s to under 40) had a bachelor degree or higher education and held white collar jobs in IT, retail, sales, or admin, within a comfortable salary range of about 10-20 million VND/month (about 500-1,000 USD). To them, health care means ensuring a fully functional body that will cope with a busy working life. As a result, most consult a specialist at the first worrying symptoms (especially female respondents), and may eat organic food and go for fitness to keep in shape. Thanks to young age and preventive care, they tend to suffer only from minor illnesses, such as cold, flu, fever, dental, and gastro ailments.

The older patients (aged 40-65) are either retired or self-employed, and must spend money wisely due to family commitments, e.g. university tuition for child. In terms of health [50-52], many suffer from chronic diseases (diabetes, cardio, joints) and see their physician regularly to monitor risk factors and may undergo major lifestyle changes such as change of diet, walking, and yoga.

\section{Perception of foreign versus local hospitals}

Generally, older middle income patients believe that local government hospitals have excellent Vietnamese doctors for treating serious illnesses (cancer, cardio, etc.), but service quality and facilities are dismal. The younger group prefer streamlined, hassle-free private care and, when employer insurance covers it, international hospitals, for the 'special attention' and modern equipment. Across all ages, respondents who experienced international hospitals remained with a lasting positive impression of feeling 'privileged' to be seen by expert doctors and pampered 'like in a 5-star hotel' [53-56].

\section{Local public hospitals}

Perception: Public hospitals have the highest awareness among older respondents, with prestigious doctors offering expert treatment for low- and mid-income patients, especially coming from the province under social health coverage. Among HCM City residents, older respondents are very familiar with public hospitals, but visits are limited to hospitalization or surgery.

Drivers and barriers: Especially older respondents trust public hospitals for reputable, expert doctors that prescribe treatment which will effectively deal with the diseases. National public hospitals are perceived to have suitable equipment (ultrasound, CT) and are quite affordable due to SHI. Despite their expertise, doctors were also the greatest barrier to public care and appeared 'rude, cold, and inconsiderate' because they readily dismiss patients. Secondly, users highlighted the insensitive support staff (nurses, X-ray technician, etc.) who 'herd us in like cattle to undress in front of everybody for $\mathrm{X}$-ray', which adds to the discomfort of worrisome symptoms. Thirdly, congested waiting areas (with family and patients sleeping in hallways), dirty toilets, bed-sharing, and unclean surroundings give an unsafe feeling and fear of infection. Finally, all respondents complained about long waiting times (up to 4-6 hours for a visit), a critical barrier for working professionals. In summary, unless carrying a critical disease or forced to seek SHI coverage due to low income, most older respondents and all younger targets are reluctant to visit public hospitals. 


\section{Private care}

Perception: Seen as careful, quick, and effective, private care has top of mind awareness and is the first stop for younger patients across all income brackets. A number of older patients who experienced the difference also traded up and away from government hospitals for common illnesses without complications.

Drivers and barriers: Respondents across all ages first notice the helpful staff that offer clear guidance, and devoted doctors who spend time to understand the patient's symptoms. Valued by the younger group, private hospitals have quick procedures and comfortable facilities (clean, modern waiting area, functional elevators) which help visitors 'calm down and feel less scared of being in a hospital.' The only quality issue raised by younger targets was running the same tests as a government hospital, but at much higher charges. Some older patients-especially those loyal to international hospitals-expressed concern over the doctors' seniority and expertise, and over-treating to gain more revenue: 'I thought I would be done in two visits, but the hospital kept delaying the diagnostic to make me come back for more tests.' Finally, all patients mentioned the higher price-an important criterion for older users with serious diseases, but of moderate significance for the healthier younger segment. To sum up, the private sector is warmly welcome by HCM City residents, especially working professionals who are willing to try new options and those who have not experienced international providers. However, conservative older patients in the mid-income bracket still trust public hospitals for the reasonable fees and effective results.

\section{International and foreign joint-venture hospitals}

Perception: All respondents who directly experienced international hospitals (SOS, Family Medical Practice) and foreign joint-venture hospitals (French-Vietnamese hospital) recalled strong, positive images of personalized care in 'a world where everyone smiles' with reassuring, 'knowledgeable doctors who really listen' and impressive 'state-of-theart equipment'. For many, it was a revelation of a new benchmark of what health care should be, and, as long as they can afford international care through their employer or personal insurance, they will never go back to local providers.

Drivers and barriers: In order of priority, patients appreciated the doctor's professional consultation-being asked about objectives and expectations, discussing pros and cons of various treatment alternatives, and receiving tips on healthy living. Among those requiring hospitalization, patients spoke highly of being visited daily by foreign doctors, and having nurses available around the clock. Secondly, most patients mentioned ethical, personalized care: patients felt that the staff and the doctors at international hospitals treated them as 'a privileged client' and did so 'out of professional responsibility rather than just for money'. Thirdly, respondents appreciated the fast and efficient processes, and the staff who accompany patients between departments and proactively assist without being asked ('the staff saw that I had trouble walking around and immediately brought a wheelchair.'). Finally, outstanding facilities gave patients a sense of reassurance about treatment quality due to detailed test results and high-tech devices that allowed the client to 'see inside my own body with a live camera'. Among those interviewed, older patients tried international care when prompted by family after local centers failed them, while the younger group tried out of curiosity after seeing the foreign brand on their employer benefit list.
The only major barrier mentioned was the high price, as much as four times compared to local alternatives 'My haemorrhoids surgery cost me 40 million (approx. 2,000 USD) here, although it would have been only 8 million (400 USD) in a government hospital and 12 million (600 USD) in a private one.' However, all those interviewed were willing to absorb the out-of-pocket expenses for general check-up and minor treatments, and co-pay when needed. Most interviewee's accessed international care through their employer and, of those who changed jobs; all chose to repurchase the hospital's personal insurance to continue to receive treatment there. High satisfaction and the perception of good value for money were consistent even among chronic patients who required costly hospitalization or frequent follow-ups far from home. A minor barrier mentioned by two patients was a support staff 'who was being Vietnamese' referring to someone scowling or being unfriendly, but both patients attributed such slips to culturally embedded habits ('I don't think it's the hospital's fault, but rather the girl forgot for a moment that she was working in an international hospital').

\section{Discussion}

This section will provide a breakdown of each choice criterion into underlying elements, followed by a presentation of factors in order of priority for public, private, and international hospitals across age groups and income levels.

\section{Factor Priority}

As reflected in the interviews, choice factors for trial and repurchase at international hospitals appear to be quite different from drivers for local public and private care. For local hospitals, the factors are, in order of priority: hospital reputation, doctor quality, customer service, facilities, location, and SHI coverage. Probing further into what reinforces each factor, it was found that hospital reputation results from word-of-mouth from current users, direct mention of a strong specialty (particularly for government hospitals), endorsement (linked to medical university for state, or international investment for private), and strong marketing communications (TV, editorials in the press). Before the visit, the perception of doctor quality is given by seniority and experience (older respondents feel most assured when the doctor has 10-15 years of work experience in a national hospital) and qualifications (PhD studies or overseas training are appreciated by older and more traditional patients). During the actual experience, doctor quality is reinforced through both technical expertise and interpersonal skill: patients expect accurate diagnostic and quick recovery (especially at government hospitals), but also a caring and devoted doctor who listens and consults in detail (this expectation is highest among the younger group at private facilities). Service is of high importance for private care among younger users as it calms them down and encourages them to return for follow-ups. Major components include staff attitude and resourcefulness (nice-to-have for private, but outstanding point of differentiation for international care), and fast, streamlined procedures (e.g. computerized registrations).

Among lesser factors, facilities are already a perceived advantage of private providers and an add-on for international hospitals. This factor is supported by: 1) Modern technology to provide accurate diagnostic and assurance; 2) A one-stop comprehensive range of testing equipment for holistic exams (no side trips to labs); 3) Clean and modern building (functional elevators, disinfected restrooms, AC, signposts) which suggests safety from infection and hospital quality. In terms of location, younger patients with minor ailments prefer hospitals within their daily commute, or accessible from different 
residential areas. Out-of-the-way location is acceptable in serious cases (surgery, cancer), especially among older consumers with affordability barrier. Finally, SHI coverage was mentioned mostly for treating chronic illness by those in the lower income bracket (under 750 USD/ month per household, non-residents).

Some variations were encountered across age and income. For lowincome patients and out-of-town referrals to state-run institutions, SHI coverage (affordability) takes a close third place in the consideration set, with all other factors remaining as above. Even in the higher income bracket, hospital reputation and doctor quality are still critical for older respondents, for chronic or serious cases (cardio, diabetes, joints) and among traditional younger users who doubt the ethics of private facilities.

Although hospital reputation is still key in the choice of private care, customer service, facilities, and location become the main triggers in the decision to trade up from government institutions. Younger working professionals irrespective of income choose private institutions for the efficient processes and convenient location, and appreciate the opportunity to be productive while waiting in the AC lounges with free Wi-Fi. Additionally, a number of older patients welcome the warm smiles and clean surroundings after dreading the poor hygiene and rude service of state-run hospitals. Doctor quality appears to be less important when opting for private providers, as patients have a strong perception that doctors here are "nice and caring, but not the best experts' and see private hospitals as offering 'a quick fix if you don't have complications'.

The general consensus among users of international health care is 'best in every way, as long as you have the money'. Within the market, international institutions have the lowest awareness, as most respondents had experienced only one provider and were unable to name others. With few exceptions, the trial trigger was employer benefit, with one interviewee picking the first foreign hospital found online after family recommendation, and another getting an indirect first impression while accompanying a relative. During the actual experience, users are most impressed with doctor quality, especially work ethics, comprehensive consultation, and a general sense that the doctor really has their best interest at heart. A close second criterion is service, in particular the friendly and proactive support staff who swiftly led patients through hassle-free processes. Finally, ultramodern equipment and premium facilities reinforce the perception that international standards are applied to identify the root cause of illness and deliver treatment in the most comfortable environment. Location was only mentioned by one respondent, but as a non-issue since he felt that the assurance of getting reliable and professional care greatly offset the inconvenience of the long commute.

\section{Findings Related to the Research Questions and Propositions}

Based on the data analysed above, the study appears to answer the research questions:

What are the choice criteria and consumer perceptions of international and foreign-joint venture hospitals in Ho Chi Minh City?

- What are key choice criteria for local patients at international hospitals in HCMC?

The key choice criteria for local patients of international hospitals in HCMC on pre-visit are: Trial triggered by exposure (through employer insurance), own research after peer recommendation (in this case, non-branded), indirect past experience (e.g. accompanying a relative), and convenient location (only one patient, younger, minor ailment). For repeat visits, factors include doctor quality (technical and interpersonal skill), excellent service (attentive staff, efficient processes), and impressive facilities (equipment, building).

- How do HCMC patients perceive international hospitals v. local public and private hospitals?

Local government hospitals are perceived as an affordable and reliable option for low income patients from the provinces, but many HCMC dwellers avoid them except for very serious illnesses due to rude doctors and staff, non-hygienic environment, and long waiting times. The majority of HCMC residents, particularly under 30, prefer private local hospitals for the friendly doctors and staff, speedy processes and comfortable facilities, but doubt their efficacy and professionalism in case of severe diseases, as it does not justify the extra cost. Irrespective of age, international hospitals are perceived as outstanding in all aspects, from doctor knowledge and work ethic, to responsive and helpful staff, fast patient management, modern and comprehensive equipment, and a 'VIP' atmosphere.

- What are key drivers and barriers when choosing international hospitals?

Key drivers for choosing international hospitals include the doctor's caring and detailed consultation, involving the patient in the treatment decision, proven efficacy over time (for chronic patients), proactive and responsive support staff who assist with procedures, comprehensive range of medical devices, and the five-star feel of amenities for inpatient care. The only serious barrier mentioned was the high cost of care, but all respondents already had renewed or were willing to renew their coverage by purchasing insurance directly from the hospital One isolated incident of staff inattentiveness was mentioned, but interviewees did not appear to hold the hospital responsible.

Although the majority of Vietnamese studies reviewed in the literature Centered on affordability, the current investigation reveals price to be an issue only for the low income patients visiting government hospitals under SHI and referral. Even for this group, cost of care was mentioned only in third place, after hospital reputation, and doctor quality. For all other interviewees, especially among younger HCMC dwellers, good customer service and streamlined processes were paramount. Finally, users of international hospitals considered quality of doctors, quality of service, and facilities as key criteria before mentioning price, and stated their decision to directly purchase the international hospital's insurance without employer support, thus confirming proposition 1 .

As identified in the literature and confirmed through this study, the great majority of local patients have a negative opinion of state hospitals in all aspects except doctor expertise and affordability. In addition, although younger targets and less traditional older users appreciate the friendly service and fast procedures in private hospitals, their view is affected by lack of trust in the doctors' ability and ethics, e.g. overmedicating. Moreover, all those interviewed appeared to have a strong positive perception of international hospitals as a new benchmark in all aspects of expertise, service, and amenities, thus confirming proposition 2 .

Based on the interviews conducted, age appears to play a part in the perception of both private and public care, but not international. As shown above, young working professionals vastly favour private hospitals for fast and convenient care with friendly doctors in pleasant 
surroundings. Conversely, older users with chronic illnesses at various income levels were more likely to visit government facilities for effective and affordable treatment, despite unpleasant conditions. Although steps were taken to vary the age of the sample, a unanimous positive opinion of foreign institutions was revealed among all age groups, thus disproving proposition 3 .

\section{Conclusion}

In the final analysis, it is felt that the study has achieved its stated objectives of identifying the perceptions of HCMC patients towards international hospitals (strongly positive) compared with local public and private hospitals, the key decision factors in choosing international care (quality of doctors, service, facilities) and the drivers and barriers towards foreign hospitals (price as the only barrier). As far as hypotheses are concerned, the study confirmed that price is not a primary criterion considered in the choice of international hospital (confirmed H1), proved that Vietnamese patients have a positive impression of international hospitals (confirmed H2), but found that, in fact, there seems to be no relationship between the patients' age and their perception of international hospitals (disproved H3).

As awareness is low but perceptions are favourable, international and foreign joint-venture hospitals in HCM City should strengthen their B2B relationship with HR Managers and have their hospital listed under employer insurance. This would lower the perceived price barrier while at the same time exposing more potential patients to trial and preventive care visits. Since hospital reputation was found to strongly link to word-of-mouth and perceived quality of doctors, international facilities should emphasize doctor's full consultation and proactive staff in their marketing communications to upper middle and higher income HCMC dwellers. To reduce the perceived affordability barrier, the foreign providers can also encourage existing buyers of the hospital's own insurance to influence peers through a friend referral system.

Although measures were taken to maximize the utility and credibility of this qualitative study by selecting highly relevant respondents of different age, gender, income, and severity of illness, a number of limitations need to be stated: The sample size is small (11 respondents) and subjected to only one research method (qualitative interviews), the study is limited to only one area of one city (medical hub in HCMC) and was conducted within approximately one month (April 2016). To expand on the current research, future investigations may include a larger sample size (e.g. 384 respondents for $95 \%$ confidence with $5 \%$ margin on error) drawn from a more representative population set (quotas for North and Central Vietnam, and for smaller towns). Future studies could use two research methods for triangulation (e.g. quantitative surveys in addition to qualitative insight) and carry them out longitudinally over a longer period. In terms of areas investigated, possible hypotheses can test the actual weight and relevance of each decision criterion, measure the impact of employer support on accessibility, or estimate the effectiveness of various communication channels in inducing trial and preference for international health care.

\section{References}

1. http://www2.deloitte.com/au/en/pages/life-sciences-and-healthcare/articles/ global-health-care-sector-outlook.html

2. http://www.marketsandmarkets.com/PressReleases/healthcare-dataanalytics.asp

3. http://www.forbes.com/sites/benjaminshobert/2014/07/31/healthcare-invietnam-part-1/\#86e39ab7e176
4. http://www.economist.com/news/asia/21618894-ordinary-folk-are-sick-andtired-their-public-hospitals-limping-along

5. Bliss M (2015) vietnam healthcare market overview.

6. http://www.tradingeconomics.com/vietnam/health-expenditure-privatepercent-of-gdp-wb-data.html

7. Schiffman L, Kanuk L (2010) Consumer behavior. New Jersey: Pearson Prentice Hall.

8. Kotler P, Keller KL (2009) Marketing management. Upper Saddle River.

9. Belch GE, Belch MA (2012) Advertising and promotion. An integrated marketing communication perspective.

10. Kotler A, Armstrong G (2010) Principles of marketing. NY, USA: Pearson Education.

11. Bose S, Ponnam A (2011) Country of origin effect on services: an evaluation of entertainment. Manag Leis 16: 98-107.

12. Berentzen JB, Backhaus C (2008) Does "Made in ..." Also Apply to Services? An empirical assessment of the country-of-origin effect in service settings. $J$ Relat Mar 7: 391-405.

13. Lanjananda P, Patterson PG (2009) Determinants of customer-oriented behaviour in a health care context. J Serv Manag 20: 5-32.

14. Taylor SL, Cosenza RM (1999) A conceptual choice model for hospital services. J Mark Theor Pract 7: 20-33.

15. Skinner TJ, Price BS (1977) Factors affecting the choice of hospital-based ambulatory care by the urban poor. Am J Public Health 67: 439-446.

16. Akinci F, Esatoğlu AE (2004) Hospital choice factors: a case study in turkey. Health Mark Q 22: 3-19.

17. Jung K, Feldman R, Scanlon D (2011) Where would you go for your next hospitalization? J Health Econ 30: 832-841.

18. Tengilimoglu $D$, Yesiltas $M$ (2007) The role of public relations activities in hospital choice. Health Mark Q 24: 19-31.

19. Moscone F, Tosetti E, Vittadini G (2012) Social interaction in patients' hospital choice: evidence from Italy. J Roy Stat Soc 175: 453-472.

20. Kamra V, Singh H, De KK (2016) Factors affecting hospital choice decisions an exploratory study of healthcare consumers in Northern India, Kamra. Asia Pacific J Healt Manag 11: 76-84.

21. Singh PP (2013) Comparison of service quality between private and public hospitals: empirical evidences from Varanasi District in up. Paradigm 1: 37-46.

22. Bhangale V (2011) Marketing of healthcare services in India: a study on factors influencing patients' decision making on choice of a hospital. J Manag Mark Healthc 4: 229-233.

23. Andaleeb SS (2001) Service quality perceptions and patient satisfaction: a study of hospitals in a developing country. Soc Sci Med 52: 1359-1370.

24. Rannan-Eliya R, Wijemanne N, Liyanage I, Dalpatadu S (2015) Quality of inpatient care in public and private hospitals in Sri Lanka. Health Policy Plan 30: $46-58$

25. Polsa $\mathrm{P}$, Spens K, Soneye A (2011) Comparing the perceived quality of private and public health services in Nigeria. J Manag Polic Prac 12: 18-26.

26. http://www.futurehealthsystems.org/publications/ensuring-health-care-for-therural-poor-social-aims-and-comm.htm

27. Doorslaer E, O'Donnell O (2006) Effect of payments for health care on poverty estimates in 11 countries in Asia: an analysis of household survey data. Lancet 368: $1357-1364$

28. Thuan NTB, Lofgren C, Lindholm L, Chuc NTK (2008) Choice of healthcare provider following reform in Vietna. BMC Health Serv Res 8: 162.

29. Khe N, Tuan N, Ericsson B (2002) Primary health concept revisited: Where do people seek health care in a rural area of Vietnam? Health Policy 61: 95-109.

30. Jowetta M, Contoyannis P (2002) The impact of public voluntary health insurance on private health expenditures in Vietnam. Soc Sci Med 56: 333-342.

31. http://heapol.oxfordjournals.org/content/20/2/90.short

32. Nguyen TK, Khuat OT, Ma S (2012) Impact of health insurance on health care treatment and cost in vietnam: a health capability approach to financial protection. Am J Public Health 102: 1450-1461. 
Citation: Bucatariu L, George BP (2017) Patient Perception and Choice Factors Related to International Hospitals: A Study in Ho Chi Minh City, Vietnam. J Health Med Informat 8: 277. doi: 10.4172/2157-7420.1000277

Page 8 of 8

33. Lonnrith K, Tran T, Le M, Diwan V (2001) Can I afford free treatment? Perceived consequences of health care provider choices among people with tuberculosis in Ho Chi Minh City, Vietnam. Soc Sci Med 52: 935-948.

34. Nguyen H, Berman P, Larsen U (2002) Household utilization and expenditure on private and public health services in Vietnam. Health Policy Plan 17: 61-70.

35. Bayarsaikhan D, Kwon S, Chimeddagva D (2015) Social health insurance development in Mongolia: Opportunities and challenges in moving towards Universal Health Coverage. Int Soc Sec Rev 68: 93-113.

36. Parmenter EM (2015) The Health Care Benefit Crisis, Ten Years Later: Part I. J Financ Serv Profes 18: 67-83.

37. Pettigrew MM, Forman HP (2015) Innovating in health care management education: development of an accelerated MBA and MPH degree program at Yale. Am J Public Health 105: 68-72.

38. Mittelstaedt J, Duke CR (2009) Health care choices in the United States and the constrained consumer: a marketing systems perspective on access and assortment in health care. J Pub Polic Mark 28: 95-101.

39. Cavusgil ST (1996) Pricing for global markets. J Worl Busin 25: 66-78.

40. Custance P, Hingley M, Wilcox D (2011) Developing a novel health and wellbeing service: The value of utilising the restorative benefits of nature in the UK. J Mark Manag 27: 384-400.

41. Došen ĐO, Bilić $\vee(2009)$ Perception among croatian surgeons of services marketing application to health care organizations. IDEAS 27: 203-218.

42. Garg P, Agarwal D (2014) Critical success factors for ERP implementation in a Fortis hospital: an empirical investigation. J Enterp Inform Manag 18: 402-423.

43. http://geert-hofstede.com/national-culture.html

44. https://www.gov.uk/government/uploads/system/uploads/attachment_data/ file/250181/List_of_Hospitals_in_Ho_Chi_Minh_City_and_Southern provinces.pdf

\section{Johansson JK (2009) Global marketing}

46. Kemp E, Min K S, Joint E (2015) Selling hope: the role of affect-laden health care advertising. J Mark Theo Prac 23: 434-454.

47. Ku L, Frogner BK (2015) Primary care. community health centers employ diverse staffing patterns, which can provide productivity lessons for medical practices. Health Aff 34: 94-103.

48. Rogers MA (2014) Managing the gaps in health care digital marketing. Mark Health Serv 34: 16-17.

49. Nix TW, Gibson JG (1989) Does a hospital's religious affiliation affect choice of hospital and patient satisfaction? J Health Care Mark 9: 40-41.

50. Perrott BE (2013) Including customers in health service design. Health Mark Q 30: 114-127.

51. Richman BD, Udayakumar K, Mitchell W, Schulman KA (2008) Lessons from india in organizational innovation: a tale of two heart hospitals. Health Aff 27 : 1260-1270.

52. Sahn DE, Younger SD (2007) The joint demand for health care, leisure, and commodities: Implications for health care finance and access in Vietnam. J Dev Stud 43: 1475-1500.

53. Saunders M, Lewis P, Thornhill A (2012) Research methods for business students. Harlow: Pearson Education Ltd.

54. http://www.jointlearningnetwork.org/news/vietnam-accelerates-universalhealth-insurance

55. Vriens M, Hofstede FT (2000) Linking attribute, benefits, and consumer values Mark Res 12: 4-10.

56. Wongrukmit P, Thawesaengskulthai N (2014) Hospital service quality preferences among culture diversity. Tot Qual Manag Busin Exc 25: 908-922. 